\title{
An evaluation of the multidisciplinary approach to psychiatric diagnosis in elderly people
}

\author{
Gill Collighan, Alastair Macdonald, Joe Herzberg, Michael Philpot, JamesLindesay
}

\begin{abstract}
Objective-To determine the accuracy of psychiatric diagnoses made by two community psychogeriatric teams operating a multidisciplinary assessment procedure.
\end{abstract}

Design-Comparison of team diagnosis with independent formal assessment and consensus diagnosis by research psychiatrists.

Setting-Two community psychogeriatric teams with similar operational policies in an inner London health district.

Subjects-100 people aged $65-90$ (70 women) newly referred to the teams.

Main outcome measures-Concordance between team and research diagnoses.

Results-Agreement between team and research diagnoses ranged from $\mathbf{9 0} \%$ to $99 \%$ for the specific psychiatric disorders studied. There was no significant difference between medical and non-medical team members in their diagnostic performance compared with the research psychiatrists. Increased diagnostic accuracy by team members was associated with longer experience of team working, regardless of the team members' professional background.

Conclusions-The multidisciplinary approach to the assessment of referrals to these community teams for the elderly is not associated with misdiagnosis of psychiatric disorder.

\section{Introduction}

Wherever comprehensive psychogeriatric services have been developed, they have usually been organised around the activities of some sort of multidisciplinary outreach team drawn from the professions of nursing, occupational therapy, psychology, social work, and psychiatry. There are good clinical reasons for this approach, since elderly people with mental disorder suffer from a complex range of mental, physical, and social problems and no one profession is adequately equipped to deal with all of these on its own. In addition, there are considerable organisational advantages if the various professionals concerned act as a team; use of staff resources is more efficient, service planning and development are facilitated, and there is better management of the caseload. ${ }^{2}$ In urban areas, where the range of health professionals at the primary care level is still variable, a fully multidisciplinary approach to the assessment and management of cases is a valuable means of compensating for the limitations of particular general practices.

For the most part, multidisciplinary psychogeriatric teams have developed as an enhanced version of the traditional service, with the consultant as the team leader and decision maker and all patients receiving formal psychiatric assessment at some point during their contact with the service. ${ }^{34}$ In some areas, however, a different model of teamwork has evolved in which the tasks of assessment and management are shared, and not all patients are necessarily seen at any time by a psychiatrist. This development is in part a response to the rapidly growing demand for psychogeriatric services as a result of demographic trends, ${ }^{5}$ and in part to an acknowledgment that the multidisciplinary nature of these services needs to be fully reflected in the way they are managed and delivered. This approach to psychogeriatric service provision is enthusiastically endorsed by its supporters, ${ }^{6}$ but others have expressed misgivings-for example, one survey has reported that referring general practitioners were suspicious of initial psychogeriatric assessments by non-medical disciplines. ${ }^{7}$ A commonly expressed concern is that assessment by non-doctors may result in misdiagnosis and subsequent mismanagement of cases. This is an important issue, and one that teams deal with by routine case review in the presence of a doctor and psychiatric reassessment wherever there is any doubt. This aspect of the teams' activity has not yet been formally evaluated. We report the findings of a study in which the psychiatric diagnoses made as part of the case assessments by two similar multidisciplinary psychogeriatric community teams were compared with formal psychiatric assessment and diagnosis.

\section{Method}

\section{THE TEAMS}

The London Borough of Lewisham is served by two multidisciplinary community teams for mental health in the elderly, which provide assessment, treatment, rehabilitation and support services to elderly mentally ill people living in this area. One team was established in 1984, the other in 1987. The teams have similar operational policies, including an open referral system, and accept cases from a wide range of agencies. Initial domiciliary assessments are carried out by either a medical or a non-medical team member by using a semistructured schedule that guides them through the various clinical, functional, social, and other components of the assessment. All cases are presented and discussed at the weekly team meeting, after which an initial diagnosis is made. Further specialist assessments by other members of the team may take place at any time during the episode of care if they are considered necessary.

\section{THE STUDY}

Between May 1990 and February 1991, 101 (27\%) of 378 new cases referred to the teams and assessed by them were independently and blindly assessed by a research psychiatrist (GC). These were cases in which the research interview could be carried out within one week of the team assessment, to minimise disagreement due to changes in the patients' condition. To control for primacy effects, approximately half of the cases were interviewed by the research psychiatrist before the team assessment, and the remainder afterwards. Eighteen patients admitted to hospital after team assessment were reviewed by the research psychiatrist and included in this study, but one subject who was seen first by the research psychiatrist and admitted after that interview as a matter of urgency was excluded, leaving a study sample of 100 cases.

The research assessment consisted of a structured psychiatric interview (the geriatric mental state $\left.(\mathrm{GMS})^{8}\right)$, a full medical and psychiatric history, a

\author{
Correspondence to: \\ Professor Lindesay. \\ BMF 1993;306:821-4
}


physical examination, and a routine blood screen which consisted of a full blood count, liver function tests, thyroid function tests, syphilis serology, and determining concentrations of urea, electrolytes, serum glucose, vitamin B-12, and folate. A collateral history was taken from other relevant informants wherever possible.

The findings of the research assessments were presented by the research psychiatrist to two independent consultant psychogeriatricians (JH, JL), and a consensus research psychiatric diagnosis was agreed. So that the research and team diagnoses would be comparable, relatively broad diagnostic categories for both were used. The research diagnoses were compared with the diagnoses made by the teams after initial case assessment and review but before any subsequent reassessment by another team member. The data from

TABLE I-Primary team diagnosis and referring agency for all new referrals and study sample. Values in parentheses are percentages

\begin{tabular}{lcc}
\hline & $\begin{array}{c}\text { Total } \\
(\mathrm{n}=378)\end{array}$ & $\begin{array}{c}\text { Study } \\
(\mathrm{n}=100)\end{array}$ \\
\hline $\begin{array}{l}\text { Primary team diagnosis: } \\
\text { Non-case }\end{array}$ & $29(8)$ & \\
Dementia & $176(47)$ & $53(3)$ \\
Delirium & $9(2)$ & $3(3)$ \\
Depression & $91(24)$ & $30(30)$ \\
Mania & $3(1)$ & $2(2)$ \\
Anxiety & $18(5)$ & $2(2)$ \\
Paranoid states and schizophrenia & $25(7)$ & $3(3)$ \\
Other & $27(7)$ & $4(4)$ \\
Referring agency: & & \\
Medical: & $206(55)$ & $57(57)$ \\
$\quad$ General practitioners & $76(20)$ & $11(11)$ \\
$\quad$ Hospital & & \\
Non-medical: & $53(14)$ & $18(18)$ \\
Community care service & $4(1)$ & $9(9)$ \\
Social worker & $10(3)$ & $8(8)$ \\
Old peoples' home & $10(3)$ & $6(6)$ \\
Relative or friend & $19(5)$ & 0 \\
Other & & \\
\hline
\end{tabular}

TABLE II-Profession of initial assessor in community team for mental health in the elderly. Values in parentheses are percentages

\begin{tabular}{lcc}
\hline Assessor's profession & $\begin{array}{c}\text { Total } \\
(\mathrm{n}=378)\end{array}$ & $\begin{array}{c}\text { Study } \\
(\mathrm{n}=100)\end{array}$ \\
\hline Medical: & $123(33)$ & $33(33)$ \\
Consultant & $36(10)$ & $6(6)$ \\
Clinical assistant & $40(11)$ & $1(1)$ \\
Senior registrar & $16(4)$ & 0 \\
Registrar & $24(6)$ & $20(20)$ \\
Senior house officer & $7(2)$ & $6(6)$ \\
Non-medical: & $255(68)$ & $67(67)$ \\
Social worker & $62(16)$ & $25(25)$ \\
Community psychiatric nurse & $85(23)$ & $24(24)$ \\
Occupational therapist & $86(23)$ & $18(18)$ \\
Psychologist & $22(6)$ & 0 \\
\hline
\end{tabular}

TABI.E III - Concordance between team and research diagnoses (all team members). Numbers include both primary and secondary diagnoses

\begin{tabular}{|c|c|c|c|c|c|c|c|}
\hline \multirow[b]{2}{*}{ Diagnosis } & \multirow{2}{*}{$\begin{array}{c}\text { Team } \\
\text { diagnoses }\end{array}$} & \multirow{2}{*}{$\begin{array}{l}\text { Research } \\
\text { diagnoses }\end{array}$} & \multicolumn{3}{|c|}{ Percentage } & \multirow{2}{*}{$\stackrel{\mathrm{k}}{\text { Statistic }}$} & \multirow{2}{*}{$\begin{array}{c}\text { Yule } \\
\text { statistic }\end{array}$} \\
\hline & & & Agreement & Specificity & Sensitivity & & \\
\hline Non-case & 3 & 2 & 99 & 99 & 100 & $0 \cdot 80$ & 0.89 \\
\hline Dementia & 55 & 63 & 90 & 97 & 86 & 0.79 & $0 \cdot 84$ \\
\hline Delirium & 4 & 3 & 97 & 98 & 67 & 0.56 & 0.78 \\
\hline Depression & 34 & 31 & 95 & 94 & 97 & 0.89 & 0.89 \\
\hline Mania & 2 & 3 & 99 & 100 & 67 & $0 \cdot 80$ & 0.89 \\
\hline Anxiety & 2 & 1 & 99 & 99 & 100 & 0.66 & $0 \cdot 87$ \\
\hline Paranoid state & 3 & 4 & 99 & 100 & 75 & $0 \cdot 85$ & 0.91 \\
\hline
\end{tabular}

the GMS interview were also analysed using AGECAT, a computerised algorithm which uses ratings on the interview to assign subjects reliably to diagnostic categories at various levels of "caseness"; AGECAT classification at the diagnostic syndrome case level was used as an independent criterion for comparison with both the team and the research diagnoses.

The data were analysed with SPSS/PC+." The concordance between the teams' and the research diagnoses and between these and the AGECAT classification is expressed here in terms of percentage agreement, specificity, sensitivity, and the kappa ( $\mathrm{\kappa}$ ) and Yule statistics. The $\kappa$ statistic is a widely used measure of observer agreement, but its value can be misleadingly low if the base rate of the condition in question is less than $20 \%$. An alternative is the coefficient of colligation (Yule statistic), which is mathematically similar to $\kappa$ but stable over a wider range of base rates. ${ }^{11}$

\section{Results}

The age range of the study sample was $65-90$ years (mean 78.2 (SD 6.64) years). There were 70 women and 30 men. The source of referrals to the teams is shown in table I, and the occupation of the initial assessor from the community teams in table II. The proportion of study cases initially assessed by more senior, non-training grades of psychiatrist (consultant or clinical assistant) was significantly lower than that of all new referrals over the study period $\left(7 \% v 20 \% ; \chi^{2}=\right.$ $8.57 ; \mathrm{p}<0.01)$. There was no difference in the proportions of patients with various diagnoses seen by the doctors and non-doctors, in terms of either team diagnosis or research diagnosis. The study sample did not differ significantly from the totality of new referrals in terms of age distribution, sex ratio, or referring agency, apart from having a lower proportion of referrals from old peoples' homes (8/100 v 10/378; $\left.\chi^{2}=4.87 ; \quad \mathrm{p}<0.05\right)$. The distribution of team diagnoses after assessment was similar to that of the new referrals as a whole (table I).

In seven cases the three research psychiatrists could not agree unanimously on the primary diagnosis; in these cases the majority opinion (2:1) was taken as the research diagnosis. Overall, there was complete agreement between the team and research diagnoses in 86 cases, and partial agreement in a further three. For specific diagnostic categories, the percentage agreement was $90 \%$ and above, with associated $\kappa$ and Yule statistics strongly indicating that these agreements were not attributable to chance alone (table III). Dementia was the diagnostic category with the highest misclassification rate in relation to the research diagnosis; in three cases the team diagnosis was deferred pending further assessment and investigation. The three cases of misclassification of delirium were due to the time delay between the team and research assessments; by the time of the second assessment, the delirium apparent at the first had substantially resolved to reveal an underlying depression or dementia, or both.

TABLE IV-Concordance between team and research diagnoses, by profession of team member. Numbers include both primary and secondary diagnoses

\begin{tabular}{|c|c|c|c|c|c|c|c|c|c|c|c|c|c|c|}
\hline \multirow[b]{3}{*}{ Diagnosis } & \multicolumn{7}{|c|}{ Doctors $(n=33)$} & \multicolumn{7}{|c|}{ Non-doctors $(n=67)$} \\
\hline & \multirow{2}{*}{$\begin{array}{c}\text { Team } \\
\text { diagnoses }\end{array}$} & \multirow{2}{*}{$\begin{array}{l}\text { Research } \\
\text { diagnoses }\end{array}$} & \multicolumn{3}{|c|}{ Percentage } & \multirow{2}{*}{$\begin{array}{c}\kappa \\
\text { Statistic }\end{array}$} & \multirow{2}{*}{$\begin{array}{c}\text { Yule } \\
\text { statistic }\end{array}$} & \multirow{2}{*}{$\begin{array}{c}\text { Team } \\
\text { diagnoses }\end{array}$} & \multirow{2}{*}{$\begin{array}{l}\text { Research } \\
\text { diagnoses }\end{array}$} & \multicolumn{3}{|c|}{ Percentage } & \multirow{2}{*}{$\begin{array}{c}\kappa \\
\text { Statistic }\end{array}$} & \multirow{2}{*}{$\begin{array}{l}\text { Yule } \\
\text { statistic }\end{array}$} \\
\hline & & & Agreement & Specificity & Sensitivity & & & & & Agreement & Specificity & Sensitivity & & \\
\hline Non-case & 0 & 0 & & & & & & 3 & 2 & 99 & 67 & 100 & 0.79 & $0 \cdot 87$ \\
\hline Dementia & 23 & 25 & 82 & 86 & 81 & 0.55 & 0.61 & 32 & 38 & 94 & 100 & 89 & 0.88 & 0.91 \\
\hline Delirium & 2 & 2 & 94 & 97 & 50 & 0.47 & 0.64 & 2 & 1 & 99 & 99 & 100 & 0.66 & 0.84 \\
\hline Depression & 12 & 9 & 88 & 83 & 100 & 0.73 & 0.81 & 22 & 22 & 97 & 98 & 96 & 0.93 & 0.91 \\
\hline Mania & 0 & 1 & 97 & 100 & 0 & 0.00 & 0.65 & 2 & 2 & 100 & 100 & 100 & 1.00 & 0.92 \\
\hline Anxiety & 0 & 0 & & & & & & 2 & 1 & 99 & 99 & 100 & 0.66 & 0.84 \\
\hline Paranoid state & 1 & 1 & 100 & 100 & 100 & 1.00 & 0.87 & 2 & 3 & 99 & 100 & 67 & 0.79 & 0.87 \\
\hline
\end{tabular}




\begin{tabular}{|c|c|c|c|c|c|c|c|c|c|c|c|c|c|c|}
\hline \multirow[b]{3}{*}{ Diagnosis } & \multicolumn{7}{|c|}{$<1$ year with team $(n=54)$} & \multicolumn{7}{|c|}{$>1$ year with team $(n=46)$} \\
\hline & \multirow{2}{*}{$\begin{array}{c}\text { Team } \\
\text { diagnoses }\end{array}$} & \multirow{2}{*}{$\begin{array}{l}\text { Research } \\
\text { diagnoses }\end{array}$} & \multicolumn{3}{|c|}{ Percentage } & \multirow{2}{*}{$\begin{array}{c}\mathbf{\kappa} \\
\text { Statistic }\end{array}$} & \multirow{2}{*}{$\begin{array}{c}\text { Yule } \\
\text { statistic }\end{array}$} & \multirow{2}{*}{$\begin{array}{c}\text { Team } \\
\text { diagnoses }\end{array}$} & \multirow{2}{*}{$\begin{array}{l}\text { Research } \\
\text { diagnoses }\end{array}$} & \multicolumn{3}{|c|}{ Percentage } & \multirow[b]{2}{*}{ 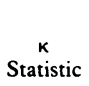 } & \multirow[b]{2}{*}{$\begin{array}{c}\text { Yule } \\
\text { statistic }\end{array}$} \\
\hline & & & Agreement & Specificity & Sensitivity & & & & & Agreement & Specificity & Sensitivity & & \\
\hline Non-case & 2 & 1 & 98 & 98 & 100 & 0.66 & 0.82 & 1 & 1 & 100 & 100 & 100 & 1.00 & 0.89 \\
\hline Dementia & 30 & 36 & 85 & 92 & 83 & 0.64 & 0.72 & 25 & 27 & 96 & 100 & 91 & 0.91 & 0.90 \\
\hline Delirium & 2 & 2 & 96 & 98 & 50 & 0.48 & 0.71 & 2 & 1 & 98 & 98 & 100 & $0 \cdot 66$ & 0.81 \\
\hline Depression & 18 & 14 & 93 & 93 & 100 & 0.31 & $0 \cdot 70$ & 16 & 17 & 96 & 100 & 97 & 0.95 & 0.92 \\
\hline Mania & 2 & 3 & 98 & 100 & 67 & 0.79 & 0.86 & 0 & 0 & & & & & \\
\hline Anxiety & 0 & 0 & & & & & & 2 & 1 & 98 & 98 & 100 & 0.66 & 0.81 \\
\hline Paranoid state & 2 & 3 & 98 & 100 & 67 & 0.79 & 0.86 & 1 & $i$ & 100 & 100 & 100 & 1.00 & 0.89 \\
\hline
\end{tabular}

TABLE VI-Concordance between GMS/AGECAT diagnostic syndrome cases and the team and research diagnoses

\begin{tabular}{|c|c|c|c|c|c|c|c|c|c|c|c|}
\hline \multirow[b]{3}{*}{ Diagnosis } & \multirow{3}{*}{$\begin{array}{l}\text { No of GMS/ } \\
\text { AGECAT cases }\end{array}$} & \multicolumn{5}{|c|}{ Team diagnosis } & \multicolumn{5}{|c|}{ Research diagnosis } \\
\hline & & \multicolumn{3}{|c|}{ Percentage } & \multirow{2}{*}{$\begin{array}{c}\mathbf{K} \\
\text { Statistic }\end{array}$} & \multirow{2}{*}{$\begin{array}{c}\text { Yule } \\
\text { statistic }\end{array}$} & \multicolumn{3}{|c|}{ Percentage } & \multirow{2}{*}{$\begin{array}{c}\stackrel{K}{K} \\
\text { Statistic }\end{array}$} & \multirow{2}{*}{$\begin{array}{l}\text { Yule } \\
\text { statistic }\end{array}$} \\
\hline & & Agreement & Specificity & Sensitivity & & & Agreement & Specificity & Sensitivity & & \\
\hline Non-case & 4 & 98 & 100 & 50 & 0.66 & 0.87 & 98 & 100 & 50 & 0.66 & 0.87 \\
\hline Organic & 56 & 91 & 89 & 93 & 0.82 & $0 \cdot 80$ & 89 & 80 & 96 & 0.77 & 0.80 \\
\hline Depression & 32 & 92 & 93 & 90 & 0.81 & $0 \cdot 81$ & 91 & 98 & 78 & 0.78 & 0.81 \\
\hline Mania & 1 & 99 & 99 & 100 & 0.66 & $0 \cdot 87$ & 99 & 99 & 100 & 0.66 & 0.87 \\
\hline Anxiety & 3 & 98 & 99 & 50 & 0.49 & $0 \cdot 78$ & 96 & 99 & 0 & 0.00 & 0.50 \\
\hline Paranoid state & 4 & 95 & 97 & 33 & 0.26 & 0.60 & 96 & 98 & 50 & 0.48 & 0.72 \\
\hline
\end{tabular}

Table IV shows the diagnostic agreements according to the profession of the team assessor. The performance of the two groups was similar across all diagnostic categories; overall, non-doctors performed slightly better against the research diagnoses, with complete agreement in 87 cases, compared with 82 for doctors, but this difference was not significant.

Table $\mathrm{V}$ shows the diagnostic agreements according to the experience of the assessor as a member of a community team for mental health in the elderly. Those with greater experience performed better, with an overall complete agreement with the research diagnosis in 93 cases, compared with 78 for the less experienced team members $(p=0 \cdot 051$, Fisher's exact probability (two tailed).

When compared with the GMS/AGECAT diagnostic syndrome case identifications, the team and research assessments performed comparably, showing good agreement in the more prevalent categories of organic illness and depression and lower concordance in rarer categories (table VI).

\section{Discussion}

This study shows that the psychiatric diagnoses made by these multidisciplinary psychogeriatric teams are very similar to those arrived at by formal research diagnostic assessment and review by psychogeriatricians. If deferred diagnoses and the artefactual disagreements involving delirium are excluded, there was complete agreement in $89 \%$ of the cases and complete or partial agreement in $92 \%$. Of course, psychiatric diagnosis is not an error free process, and it is possible that in a proportion of the cases where there was diagnostic disagreement it was the research assessment that was in error; it should be noted that in some cases the research psychiatrists could not agree among themselves on the diagnosis.

It is important to emphasise that this study is not a full and formal validation of the teams' activities. Firstly, it has examined only one aspect of the assessment process; it does not consider the functional, financial, behavioural, and social aspects, all of which are arguably as important as clinical diagnosis in planning patients' management. Another important aspect of assessment not addressed by this study is that of physical disorder. Secondly, this is not a comparative evaluation of different models of service, since the standardised diagnostic assessment carried out in this study by the research psychiatrist is not the same process of assessment that occurs in domiciliary visits performed by psychogeriatricians in more traditional services.

The close agreement between the teams' assessment diagnoses and those made by formal psychiatric review is reassuring, in that the multidisciplinary approach to initial assessment seems not to lead to misdiagnosis of patients. In this study there was no significant difference in the diagnostic performance of doctors and nondoctors; in fact, this study indicates that the team members' experience of working in the community team is a more important determinant of diagnostic accuracy than their professional background. Many of the initial assessments by doctors in this study were carried out by trainee psychiatrists who spent only six months with the team as part of their training; had the proportion of assessments by consultant psychogeriatricians and clinical assistants in the sample been more representative, the agreements between team and research diagnoses might have been closer still.

The teams involved in this study are mature and well managed, and the findings may not be relevant to "younger," less developed teams where greater medical supervision of and involvement in assessment is necessary. All multidisciplinary teams operating this model of service require clear procedures, firm management, appropriate training," and ongoing professional and clinical supervision if they are to perform well ${ }^{12}$-a point that is insufficiently appreciated by both supporters and critics of this model of service.

The role of the consultant psychogeriatrician in this service is different from that in the conventional model; rather than being the principal performer of the initial diagnostic assessments, he or she is directly involved in assessing only dubious, difficult, and urgent cases. This frees valuable time for the supervision and training of trainee psychiatrists and other team members in the assessment and management of patients and for the developmental, managerial, and audit tasks that are increasingly necessary for the efficient running of a modern comprehensive psychogeriatric service.

Changing demography and limited resources mean that manpower issues will be increasingly important for the provision of health services in the years to come, not only in less glamorous specialties such as old age psychiatry but in all areas of medicine. ${ }^{13} \mathrm{~A}$ broad and imaginative approach to this problem is needed; the 
existing skill mix and the capacity of other health professionals to carry out tasks previously restricted to scarce and expensive professionals, such as doctors, must be examined. The model of multidisciplinary teamwork that has emerged in old age psychiatry potentially provides a means whereby the valuable experience of the several disciplines concerned can be applied to the widest possible range of those who need it. However, further evaluation is needed of the other important aspects of psychogeriatric assessment, and of the long term outcomes associated with this particular style of service.

We thank the members of the two community teams and their patients for their help and cooperation with this study. This study was funded by the Lewisham and North Southwark Health Authority and the Redwood Trust and received support from Research and Development for Psychiatry.

1 Øvretveit J. Essentials of multidisciplinary team organisation. Uxbridge: Brunel University, BIOSS, 1988.

2 McGrath, M. Multi-disciplinary teamwork. Aldershot: Avebury, 1991
3 Arie T, Jolley D. Making services work: organisation and style of psychogeriatric services. In: Levy R, Post F, eds. The psychiatry of late life. Oxford: Blackwell, 1982.

4 Jolley D, Arie T. Developments in psychogeriatric services. In: Arie T, ed. Recent advances in psychogeriatrics. Vol 2. London: Churchill Livingstone, 1992 .

5 Coles RJ, Von Abendorff R, Herzberg JL. The impact of a new community mental health team on an inner city psychogeriatric service. Int $\mathcal{f}$ Geriatric Psychiatry 1991;6:31-9.

6 Murphy E. Why teams succeed. In: Lindesay J, ed. Working out: setting up and running community psychogeriatric teams. London: Research and Development for Psychiatry, 1991 .

7 Gelhaar E. Service evaluation in old age psychiatry: using the general practitioner's view. Psychiatric Bulletin 1988;12:428-30.

8 Copeland JRM, Kelleher MJ, Kellett JM, Gourlay AJ, Gorland BJ, Fliess JL et al. A semi-structured interview for the assessment of diagnosis and mental et al. A semi-structured interview for the assessment of diagnosis and mental
state in the elderly: the geriatric mental state schedule: development and

reliability. Psychol Med 1976;6:439-49.
SPSS/PC+. Statistical package for the sacial

9 SPSS/PC+. Statistical package for the social sciences. Chicago: SPSS, 1986.

10 Spitznagel EL, Helzer JE. A proposed solution to the base-rate problem in the kappa statistic. Arch Gen Psychiatry 1985;42:725-8.

11 Mental Health Services Joint Training Group (Guy's and Lewisham Trust). Brian's first case: multidisciplinary assessment of mental health problems in the elderly. East Sussex: Outset Publishers, 1991

12 Lindesay J, ed. Working out: setting up and running community psychogeriatric teams. London: Research and Development for Psychiatry, 1991.

13 Brearley S. Leading for health: manpower. BMF 1992;304:832-4.
Department of

Epidemiology and Public Health, University of Leicester, Leicester Royal Infirmary, PO Box 65, Leicester LE2 7LX

Michael Clarke, professor of epidemiology

Elizabeth S Mason, research associate

David G Clayton, senior

lecturer in medical statistics

Department of Obstetrics and Gynaecology,

University of Leicester

John MacVicar, professor of

obstetrics and gynaecology

Correspondence to:

Professor Clarke.

$B M 7$ 1993;306:824-7

\title{
Evaluating perinatal mortality rates: effects of referral and case mix
}

\author{
Michael Clarke, Elizabeth S Mason, John MacVicar, David G Clayton
}

\section{Abstract \\ Objective-To evaluate perinatal mortality rates} as a method of auditing obstetric and neonatal care after account had been taken of transfer between hospitals during pregnancy and case mix.

Design-Case-control study of perinatal deaths.

Setting-Leicestershire health district.

Subjects-1179 singleton perinatal deaths and their selected live born controls among 114362 singleton births to women whose place of residence was Leicestershire during 1978-87.

Main outcome measure-Crude perinatal mortality rates and rates adjusted for case mix.

Results-An estimated 11701 of the 28750 women booked for delivery in general practitioner maternity units were transferred to consultant units during their pregnancy. These 11701 women had a high perinatal mortality rate $(16 \cdot 8 / 1000$ deliveries $)$. Perinatal mortality rates by place of booking showed little difference between general practitioner units $(8 \cdot 8 / 1000)$ and consultant units (9.3-11·7/1000). Perinatal mortality rates by place of delivery, however, showed substantial differences between general practitioner units $(3 \cdot 3 / 1000)$ and consultant units $(9 \cdot 4-12 \cdot 6 / 1000)$ because of the selective referral of high risk women from general practitioner units to consultant units. Adjustment for risk factors made little difference to the rates except when the subset of deaths due to immaturity was adjusted for birth weight.

Conclusion-Perinatal mortality rates should be adjusted for case mix and referral patterns to get a meaningful result. Even when this is done it is difficult to compare the effectiveness of hospital units with perinatal mortality rates because of the increasingly small subset of perinatal deaths that are amenable to medical intervention.

\section{Introduction}

Evaluation in obstetrics is well developed, and the confidential enquiry into maternal mortality serves as a model for other mortality reviews.' The House of Commons Social Services Committee, however, has recently repeated its recommendation, first made in
1980, that epidemiological reviews of perinatal mortality rates should also be established. ${ }^{2}$ The Department of Health has endorsed this by requiring regional health authorities to establish epidemiological surveys of all stillbirths and neonatal deaths. ${ }^{3}$ In addition obstetricians conduct audits of their services and health authorities attempt to make purchasing decisions using, among other things, data on perinatal mortality.

While we welcome the use of such reviews, it is important that appropriate comparisons are made so that correct conclusions are drawn from differing perinatal mortality rates. For example, how can the perinatal mortality rate of an affluent part of East Anglia, with its low incidence of congenital malformations, be compared with that of an inner city area in south Wales, where a higher incidence of congenital malformation is combined with social disadvantage?

Since the mid-1970s we have reviewed perinatal mortality rates in Leicestershire to describe the cause and number of perinatal deaths and to use this information to influence local services. This report describes the referral patterns of women during pregnancy and the effect this has on the interpretation of perinatal risk; compares crude perinatal mortality rates between different maternity units; shows how adjustment for case mix influences the initial rates; and suggests ways of making analyses of perinatal mortality rates more relevant for evaluating obstetric and neonatal care.

\section{Subjects and methods}

SAMPLE POPULATION

In 1981 the population of Leicestershire was 845000 , of whom about 60000 originated from the Indian subcontinent. The data below relate to the 1179 perinatal deaths that occurred in the 114362 singleton deliveries to women resident in Leicestershire during 1978-87 regardless of place of delivery.

\section{STUDY DESIGN}

We used a case-control design with cases defined as perinatal deaths occurring among women whose place of residence was Leicestershire. The control for 